\title{
Increased Corpora Lutea
}

National Cancer Institute

\section{Source}

National Cancer Institute. Increased Corpora Lutea. NCI Thesaurus. Code C147495.

An increase in the number of corpora lutea within the ovary. 